REVIEW ARTICLE

\title{
Vulnerabilidad cardiovascular en adultos mayores con COVID-19: conociendo los mecanismos biológicos
}

\section{Cardiovascular vulnerability in COVID-19 elderly patients: getting into the biological mechanisms}

\author{
Daniela J. Cataneo-Piña ${ }^{1}$, Laura Álvarez-Gutierrez', Ramiro P. Correa-Carrera ${ }^{1}$, David U. Domínguez-Rivera ${ }^{2}$ \\ y Luis A. Lasses y Ojeda ${ }^{1,2 *}$ \\ ${ }^{1}$ Servicio de Cardiología Geriátrica, Instituto Nacional de Cardiología Ignacio Chávez; ${ }^{2}$ Universidad Autónoma de México. Mexico City, México
}

\begin{abstract}
The COVID-19 pandemic has had an important impact on older adults, conferring a worse prognosis. Older adults may have atypical presentations, which can delay the diagnosis of the disease, making its evolution more unfavorable. In addition to the cardiovascular damage mechanisms conferred by SARS-CoV-2 infection, the changes inherent in the aging cardiovascular and immune system favor the appearance of cardiovascular complications in a more relevant way in this population. The objective of this article will be to summarize the knowledge about cardiovascular involvement in older adults and explain its pathophysiological mechanisms, to alert about the early recognition and timely treatment of these complications.
\end{abstract}

Key words: Aging. Cardiovascular. COVID-19. Inflammatory. Elderly.

\section{Resumen}

La pandemia por COVID-19 ha impactado de forma importante en los adultos mayores, confiriéndoles un peor pronóstico. Los adultos mayores pueden tener presentaciones atípicas, las cuales pueden retrasar el diagnóstico de la enfermedad, haciendo su evolución más desfavorable. Además de los mecanismos de daño cardiovascular conferidos por la infección por SARS-CoV-2, los cambios inherentes al sistema cardiovascular e inmune ya envejecido, favorecen la aparición de complicaciones cardiovasculares de forma más relevante en esta población. El objetivo de este artículo será resumir los conocimientos sobre el involucro cardiovascular en adultos mayores y explicar los mecanismos fisiopatológicos de este, para alertar sobre el reconocimiento temprano y tratamiento oportuno de estas complicaciones.

Palabras clave: Envejecimiento. Cardiovascular. COVID-19. Inflamación. Adultos Mayores.

\section{Introduction}

Since the coronavirus disease outbreak in December 2019, in Wuhan, China, the disease has spread to the five continents, and there have been reported more than 3 million cases and 250 thousand deaths worldwide to the date ${ }^{1}$. This new type of coronavirus, SARSCoV-2, belonging to the beta-generae, has been isolated from the lower respiratory tract, causing severe

\section{Correspondence:}

*Luis A. Lasses y Ojeda

E-mail: alasses@yahoo.com DOI: 10.24875/ACM.20000207
Date of reception: 08-05-2020 Date of acceptance: 06-07-2020
Disponible en internet: 03-08-2020 Arch Cardiol Mex. 2021;91(Supl):74-78 www.archivoscardiologia.com 1405-9940 / @ 2020 Instituto Nacional de Cardiología Ignacio Chávez. Published by Permanyer. This is an open access article under the CC BY-NC-ND license (http://creativecommons.org/licenses/by-nc-nd/4.0/). 
acute respiratory syndrome, within other manifestations, known as COVID-192. As in the case of other coronaviruses that cause human diseases, such as SARS-CoV-1 and MERS-CoV, this new virus shares some characteristics, such as the high genetic relatedness, similar viral life cycle, transmission through respiratory droplets, and a similar timing of symptom onset and detection ${ }^{3}$.

The fatality rate of this disease varies according to demographic characteristics in each country since COVID-19 is more lethal in the older population. The overall fatality rate in Italy is higher than in China, and this could be associated with the distribution of the cases that in Italy were $37.6 \%$ of individuals aged 70 years or older, which represented $11.9 \%$ of cases in China. Nevertheless, mortality rates are similar for patients aged 80 years and older in both countries $(21.9 \%$ in China vs. $20.2 \%$ in Italy) ${ }^{4}$. Globally, the case fatality rate is estimated to increase with age. The mortality risk for males is greater; for female in their 60-69, the fatality rate is around $4 \%$, while for males of the same age it is $6.22-7.15 \%$, and it reaches $18 \%$ for female older than 80 years and $28-30 \%$ for males of this age ${ }^{5}$.

In addition to being the population prone to higher mortality, older adults face other challenges, such as exposure to asymptomatic carriers in nursing homes that favor transmission, the atypical presentation of symptoms, ageist discourses, and cognitive decline that hinders their adaptation to this pandemic ${ }^{6}$. Moreover, a greater burden of comorbidities is found in older adults, which confers a poor prognosis when diagnosed with COVID-19?.

Beyond the respiratory damage conferred by SARSCoV-2, the cardiovascular involvement associated with COVID-19 gives a poor prognosis, and older adults are more susceptible to these because of aging-related factors. This article aims to summarize the most relevant points of the clinical presentation in the elderly, the cardiac involvement associated with the disease, and explain the pathophysiological mechanisms underlying the poor prognosis in this population.

\section{Clinical presentation in older adults}

The most common symptoms in infected older patients include fever, fatigue, dry cough, dyspnea, and fatigue $^{8,9}$. Clinical manifestations such as fever or dyspnea are associated with the progression of the disease $^{8}$. Nonetheless, some patients may present afebrile or with low-grade fever, which may increase the difficulty of identifying and therefore, diagnosing COVID-199.
The atypical disease presentations such as delirium, falls and functional decline, are common in frail elderly patients due to impaired homeostasis, associated with age-related physiological changes ${ }^{10}$. It is estimated that delirium could be present in one-third of hospitalized COVID-19 patients of all ages, and two-thirds of those with severe disease ${ }^{11}$. These presentations are associated with adverse health outcomes and poor prognosis $^{12}$, so it is essential to recognize this group of patients to ensure monitoring and timely treatment.

Some laboratory parameters, such as aspartate amino transferase, creatinine, procalcitonin, D-dimer, high sensitivity cardiac troponin I (HsTnl), serum ferritine, lactate dehydrogenase and IL-6 predicted higher mortality in some observational studies ${ }^{13}$. This findings are more frequent in older adults, compared with the younger, which can reflect a greater incidence of heart, liver and kidney injury in this patients. ${ }^{14}$ Regarding to the imaging findings, compared with patients less than 65 years of age, the older patients show a greater proportion of double lung disease $\mathrm{e}^{15}$ and combined pleural effussion ${ }^{16}$.

Older adults infected with COVID-19 have frequently coexisting medical conditions, the more common being hypertension, COPD, coronary heart disease, diabetes, and cerebrovascular disease ${ }^{8,16}$. The presence of these diseases is an independent risk factor for patients with COVID-197. In a meta-analysis that included 3027 patients within thirteen studies, the proportion of underlying diseases, such as the previously mentioned, were significantly higher in critical patients, compared with the non-critical ${ }^{17}$, and the existence of multiple comorbid health conditions increase the risk of mortality around sixteen times ${ }^{9,15}$.

\section{Cardiac involvement in COVID-19 elderly patients}

Other known coronaviruses, SARS-CoV and MERS$\mathrm{CoV}$, have resulted in cardiovascular complications, such as myocardial infarction, diastolic dysfunction, transient cardiomegaly, and atrial fibrillation ${ }^{18}$. SARSCOV-2 infection is also associated with a significant burden of cardiovascular complications; in observational studies, the rate of myocardial injury is about $20 \%$, determined as elevated levels of HsTnl ${ }^{19}$, and its onset plays a vital role in the prognosis of these patients ${ }^{20}$. In a systematic review that included 4189 confirmed COVID-19 patients, from 28 studies, they found that cardiac damage, which existed before multiple organ 
dysfunction syndrome in several cases, was associated with four times higher mortality ${ }^{21}$.

Older patients with a greater burden of comorbidities are more likely to develop cardiac injury when diagnosed with COVID-1921. These patients have evidence of more severe systemic inflammation and a higher incidence of acute respiratory distress syndrome, which leads to the explanation of the diverse mechanisms of cardiac involvement in this particular population ${ }^{22}$.

Aging is a risk factor for cardiovascular disease, the cellular senescence, excessive oxidative stress, increased generation of free radicals, and chronic lowgrade inflammation, lead to mitochondrial dysfunction in aging cardiomyocytes, protein aggregates formation, and myocardial fibrosis, which are reflected in major age-related cardiac changes such as left ventricular hypertrophy, the decline in its diastolic function and left atrial dilation ${ }^{22}$. These changes may predispose to the occurrence of cardiovascular complications such as atrial fibrillation, left ventricle dysfunction, and higher incidence of myocardial infarction in the elderly when infected by SARS-CoV-2.

It is worth considering the immune changes associated with aging that perpetuate dysregulated inflammation associated with SARS-CoV-2 infection. As previously mentioned, aging is associated with a chronic, low-grade inflammatory state, characterized by a senescence-associated secretory phenotype that promotes cytokine dysregulation, with an increase of pro-inflammatory mediators such as IL- $1 \alpha, \mathrm{IL}-6$ and reduction of anti-inflammatory cytokines as IL-10 and adiponectin ${ }^{23}$. This phenotype, also known as inflamm-ageing augment the risk of CV morbidity and mortality ${ }^{24}$. The cytokine dysregulation that exists in the aged immune system is exacerbated in COVID-19 patients, and it results in ineffective activation of cytotoxic CD8+ T lymphocytes and ineffective viral clearance, as well as weak antibody production and macrophage activation that release cytokines that promote endothelial activation, inflammatory cell infiltration, and vascular inflammation, as well as procoagulant factors that enhance a prothrombotic state ${ }^{25}$.

It has been well documented that as individuals age, body composition changes, studies have shown that fat mass increases and muscle mass decreases with age. In addition to the already known impact of these body modifications, on the pharmacokinetics; it has been proposed that adipose tissue may act as a reservoir for more extensive viral spread with increased shedding, immune activation and cytokine amplification. This mechanism could partially explain the excessive pro-inflammatory response to extensive viral infection in older adults, which may lead to fatal outcomes ${ }^{26}$.

Coupled with the aging-related cardiac and immune changes, several other mechanisms of cardiac involvement have been proposed. In the endomyocardial biopsy of a patient with COVID-19 that developed cardiogenic shock, pathologic study showed low-grade interstitial and endocardial inflammation. Also, there were found groups of viral particles with the morphology and size of coronaviruses in the damaged interstitial cells ${ }^{27}$. This myocardial involvement has also been found in cardiac imaging of patients with SARS-CoV-2 infection, even without respiratory symptoms, manifested by hypokinesis and reduction in the left ventricle ejection fraction ${ }^{28}$. Beyond the viral invasion to the myocardial cells and its subsequent damage, hypoxemia may also cause cardiac injury by reducing the energy supply, increasing anaerobic fermentation, and causing intracellular acidosis and destroying the cell membrane ${ }^{17}$.

SARS-CoV-2 enters cells to trigger infection through the ACE2 receptor, in concert with the host's TMPRSS2 membrane protease that facilitates the virus entry to the cell $^{29}$. The main role of this receptor is to convert angiotensin II to angiotensin 1-7, a peptide which opposes the pro-inflammatory, pro-oxidative, vasoconstrictive and fibrotic properties of angiotensin $\|^{30}$. ACE2 is expressed in the heart, kidneys, gastrointestinal tract, vessels, and the lung alveolar epithelial cells and the upper airway tissue, and its upregulated in those patients using ACEI/ ARBs, considering the last a risk factor for disease severity. In senescent cells, there is over-expression of CD26 and ACE-2 receptors, which have been proposed as a site for SARS-CoV-2 entry to the cell. Senescent cells also show an increased propensity for enhanced protein synthesis, which is required to produce large amounts of inflammatory cytokines, and make them an ideal host target for viral replication ${ }^{31}$. As a large number of elderly patients have comorbidities such as hypertension, diabetes, and heart failure, many of them are receiving ACEls and ARBs, which may up regulate ACE2 receptors, giving more sites for viral infection. Nevertheless, the regulation of the RAS by these medications counteracts the pro-inflammatory activity of angiotensin II, giving a protective effect. In a recent meta-analysis which included nine studies and 80,526 patients, that analyzed the effect of RAAS inhibitors on the susceptibility and prognosis of COVID-19; it was found no significant association between the likelihood of testing positive for COVID-19 and the use of ACEI (OR 0.96; IC 95\% 0.88-1.04, $p=0.29$ ), or ARBs (OR 0.99; IC 95\% 
0.91-1.08, $p=0.90)$. Similarly, no significant difference was observed in mortality rate among hypertensive patients prescribed RAAS inhibitors compared to hypertensive patients taking a different treatment (OR 0.57; IC 95\% 0.20-1.33, $p=0.25)^{32}$. Whether ACEls and ARBs must be discontinued or not, is still debatable; currently, there is insufficient evidence for recommending its suspension, and the withdrawal of these RAAS blockers may confer a greater risk for further cardiac illnesses decompensation ${ }^{33,34}$.

Microvascular inflammation and thrombi also have been observed in people with COVID-19, which could be induced by the expression of adhesion molecules for endothelial activation, inflammatory cell infiltration, and vascular inflammation, which induce the endothelium to become pro-adhesive and pro-coagulant ${ }^{35}$. When these phenomena are imposed on an aged vasculature, characterized by stiffened vessels with an impaired vasomotor response ${ }^{36}$, then we obtain a medium prone to ischemic and thrombotic events, which may explain the high incidence of stroke, myocardial infarction, and venous thromboembolism in COVID-19 patients $^{37}$.

This set of mechanisms of myocardial injury explains the fact that cardiac failure is more likely to occur in patients infected with SARS-CoV-2. Along with cardiac myocyte injury, the hyperactivation of the cardiac sympathetic system, mediated by inflammatory reflexes, may be a trigger for life-threatening arrhythmic events, which could be worsened by drugs causing QTc prolongation ${ }^{38}$. This risk is increased in elderly patients due to autonomic dysfunction, the decline in the number of nodal cells in the SA and AV node and its replacement by adipose fibrotic tissue ${ }^{39}$.

In conclusion, there are multiple mechanisms of cardiovascular injury in patients infected with SARS-CoV-2, which include viral invasion to the target tissues, excessive inflammatory response, and hypoxemia. When these insults are imposed on an already aged cardiovascular and immune system, the results could be fatal, giving elderly patients a worse prognosis. In spite of the fact that the evolution of elderly patients is unfavorable, we should not exclude them from receiving optimal management when diagnosed with COVID-19. Instead, we aim to encourage the close monitoring of the cardiovascular condition of these patients, in order to identify potentially reversible cardiac complications. As in the case of other coronaviruses, patients with COVID-19 may have an elevated long-term cardiovascular risk because of a persistent systemic inflammatory activity that may lead to hyperlipidemia, glucose metabolism disorders, and accelerated cardiovascular aging. ${ }^{40}$ Surveillance of cardiovascular complications is going to be essential for the survivors of COVID-1941.

\section{Conflicts of interest}

The authors deny any conflict of interest related to the preparation of this manuscript.

\section{Ethical disclosures}

Protection of human and animal subjects. The authors declare that no experiments were performed on humans or animals for this study.

Confidentiality of data. The authors declare that no patient data appear in this article.

Right to privacy and informed consent. The authors declare that no patient data appear in this article.

\section{References}

1. COVID-19 situation update worldwide European Centre for Disease Prevention and Control [Accessed 5 May 2020] https://www.ecdc.europa.eu/ en/geographical-distribution-2019-ncov-cases.

2. Guan W.J., Ni Z.Y. Zhong N.S., et al. Clinical characteristics of 2019 novel coronavirus infection in China. Med Rxiv, 2020, [Epub ahead of print]. https://doi.org/ 10.1101/2020.02.06.20020974.

3. Wölfe, R., Corman, V.M., Guggemos, W., et al. Virological assessment of hospitalized patients with COVID-2019. Nature 2020 April 1. doi: 10.1038/s41586-020-2196-x

4. Onder, G., Rezza, G. and Brusaferro, S. et al. Case-Fatality Rate and Characteristics of Patients Dying in Relation to COVID-19 in Italy. JAMA. 2020 Mar 23. doi: 10.1001/jama.2020.4683.

5. Global COVID-19 Case Fatality Rates. Oxford COVID-19 Evidence Service. Centre for Evidence-Based Medicine. [Accessed May 5, 2020.] https://www.cebm.net/covid-19/global-covid-19-case-fatality-rates.

6. Brooke J, Jackson D. Older people and COVID-19: Isolation, risk and ageism. Journal of Clinical Nursing. 2020. https://doi.org/10.1111/jocn.15274.

7. Wang, B., Li R., Lu Z, Huang Y. Does comorbidity increase the risk of patients with COVID-19: evidence from meta-analysis. Aging (Albany NY). 2020 Apr 8;12(7):6049-6057. doi: 10.18632/aging.103000.

8. Zheng, Z., Peng, F., Xu, B., Zhao, J., et al.. Risk factors of critical \& mortal COVID-19 cases: A systematic literature review and meta-analysis. Journal of Infection. April 28, 2020;15:12. https://doi.org/10.1016/j.jinf.2020.04.021

9. Niu, S., Tian, S., Lou, J., Kang, X., Zhang, L., Lian, H. and Zhang, J. Clinical characteristics of older patients infected with COVID-19: A descriptive study. Archives of Gerontology and Geriatrics. $10 \mathrm{Apr}$ 2020, 89:104058.

10. Jarret P, Rockwood K, Carver D, Stolee P, Cosway S. Illness Presentation in Elderly Patients. Arch Intern Med. 1995;155(10):1060-1064. doi:10.1001/archinte.1995.00430100086010

11. The Harvard Gazzette. A silent epidemic. [Accessed 6 May, 2020]. https://news.harvard.edu/gazette/story/2020/04/one-third-of-hospitalizedcovid-19-patients-show-signs-of-delirium/.

12. Hofman M, van den Hanenberg F, Sierevelt I, Tulner $C$. Elderly patients with an atypical presentation of illness in the emergency department. Neth J Med. 2017 Jul;75(6):241-246.

13. Zhou Fei, Yu Ting, Ronghui Du, Fan Guohui, Liu Ying, et al. Clinical course and risk factors for mortality of adult inpatients with COVID-19 in Wuhan, China: a retrospective cohort study. The Lancet 2020; 395: 10541062. doi: https://doi.org/10.1016/S0140-6736(20)30566-3.

14. Lian, J., et al. Analysis of Epidemiological and Clinical features in older patients with Corona Virus Disease 2019 (COVID-19) out of Wuhan, Clin Infect Dis. 2020 Mar 25 .Published online 2020 Mar 25. doi: 10.1093/cid/ciaa242.

15. Liu, K., Chen, Y., Lin, R., Han, K. Clinical features of COVID-19 in elderly patients: A comparison with young and middle-aged patients. $\mathrm{J}$ Infect. 2020 Mar 27. S0163-4453(20)30116-X. doi: 10.1016/j. jinf.2020.03.005. 
16. TieLong C., Zhe D., Pingzheng M.,et al. Clinical characteristics and outcomes of older patients with coronavirus disease 2019 (COVID-19) in Wuhan, China (2019): a single-centered, retrospective study. J Gerontol A Biol Sci Med Sci. 2020 Apr 11 : glaa089. 2020 Apr 11. doi: 10.1093/ gerona/glaa089.

17. Li, B., Yang, J., Zhao, F., Zhi, L., Wang, X., Liu, L., et al. Prevalence and impact of cardiovascular metabolic diseases on COVID-19 in China. Clin Res Cardiol 109, 531-538 (2020). https://doi.org/10.1007/s00392-020-01626-9.

18. Madjid, M., Safavi-Naeini, P., Solomon, S., Vardeny, O. Potential Effects of Coronaviruses on the Cardiovascular System. JAMA Cardiol. 2020 Mar 27. doi: 10.1001/jamacardio.2020.1286.

19. Shi, S., Qin, M., Shen, B., et al. Association of Cardiac Injury With Mortality in Hospitalized Patients With COVID-19 in Wuhan, China. JAMA Cardiol. 2020 Mar 25. doi: 10.1001/jamacardio.2020.0950.

20. Guo, T., Fan, Y., Chen, M., Wu, X., Zhang, L., He, T., Wang, H., Wan, J., Wang, X. and Lu, Z. Cardiovascular Implications of Fatal Outcomes of Patients With Coronavirus Disease 2019 (COVID-19). JAMA Cardiol. March 27, 2020. doi:10.1001/jamacardio.2020.1017.

21. Bonow R, Fonarow G, O'Gara P, Yancy C. Association of Coronavirus Disease 2019 (COVID-19) With Myocardial Injury and Mortality. JAMA Cardiology. doi:10.1001/jamacardio.2020.1105

22. Triposkiadis F, Xanthopoulos A, Butler J. Cardiovascular Aging and Heart Failure. Journal of the American College of Cardiology. 2019; 74: 804 814. https://doi.org/10.1016/j.jacc.2019.06.053

23. Rea IM, Gibson DS, McGilligan V, McNerlan SE, Alexander HD and Ross OA (2018) Age and Age- Related Diseases: Role of Inflammation Triggers and Cytokines. Front. Immunol. 9:586. doi: 10.3389/fimmu.2018.00586

24. Jaiswal S, Libby P. Clonal haematopoiesis: connecting ageing and inflammation in cardiovascular disease. Nature Reviews 2020. https://doi. org/10.1038/s41569-019-0247-5

25. Liu P, Blet A, Smyth D, Li H. The Science Underlying COVID-19: Implications for the Cardiovascular System. 10.1161/circulationaha.120.047549

26. MacDaragh P, Caplice N. Is Adipose Tissue a Reservoir for Viral Spread, Immune Activation and Cytokine Amplification in COVID-19. doi:10.1002 oby. 22843

27. Tavazzi G, Pellegrini C, Maurelli M, et al. Myocardial localization of coronavirus in COVID-19 cardiogenic shock. doi: 10.1002/ejhf.1828

28. Inciardi, R., Lupi, L., Zaccone, G., Italia, L., Raffo, M., Tomasoni, D. Cani, D., Cerini, M., Farina, D., Gavazzi, E., Maroldi, R., Adamo, M., Ammirati, E., Sinagra, G., Lombardi, C and Metra, M., 2020. Cardiac Involvement in a Patient With Coronavirus Disease 2019 (COVID-19). JAMA Cardiology.
29. Hoffmann $M$, Kleine-Weber $H$, Schroeder $S$, Kruger $N$, Herrler $T$, Erichsen S, Schiergens TS, Herrler G, Wu NH, Nitsche A, Muller MA, Drosten $\mathrm{C}$ and Pohlmann S. SARS-CoV-2 Cell Entry Depends on ACE2 and TMPRSS2 and Is Blocked by a Clinically Proven Protease Inhibitor. Cell. 2020 Mar 4. Doi: 10.1016/j.cell.2020.02.052

30. Sommerstein R, Kochen M, Messerli F, Grani C. Coronavirus Disease 2019 (COVID-19): Do Angiotensin-Converting Enzyme Inhibitors/Angiotensin Receptor Blockers Have a Biphasic Effect? J Am Heart Assoc. 2020;9:e016509. DOI: 10.1161/JAHA.120.016509

31. Sargiacomo C, Sotgia F, Lisanti M. COVID-19 and chronological aging: senolytics and other anti-aging drugs for the treatment or prevention of coronavirus infection? Aging 2020: 1-7. doi: 10.18632/aging.103001.

32. Shariq M, Siddiqi T, Shahzeb M, et al. A Meta-Analysis of the Relationship Between Renin-Angiotensin-Aldosterone System Inhibitors and COVID-19. The American Journal of Cardiology(2020), doi: https://doi.org/10.1016/j.amjcard.2020.05.038

33. Position Statement of the ESC Council on Hypertension on ACE-Inhibitors and Angiotensin Receptor Blockers. European Society of Cardiology. https://www.escardio.org/Councils/Council-on-Hypertension-(CHT)/ News/position-statement-of-the-esc-council-on-hypertension-on-ace-inhibitors-and-ang. (Accessed on May 6, 2020).

34. Vaduganathan M, Vardeny O, Michel T, Murray J, Pfeffer M, Solomon S. Renin-Angiotensin-Aldosterone System Inhibitors in Patients with Covid-19. N Engl J Med 2020; 382:1653-1659. DOI: 10.1056/NEJMsr2005760

35. Boisrame-Helms J, Kremer H, Schini-Kerth V and Meziani F. Endothelial dysfunction in sepsis. Curr Vasc Pharmacol. 2013;11:150-60

36. Ungvari Z, Tarantini S, Donato A, Galvan V, Csiszar A. Mechanisms of Vascular Aging. Circ Res. 2018 Sep 14; 123(7): 849-867.

37. Middeldorp S, Coppens M, Haaps T, Foppen M, Vlaar A, Muller M, et al. Incidence of venous thromboembolism in hospitalized patients with $\mathrm{CO}$ VID19. J Thromb Haemost. 2020 May 5. https://doi.org/10.1111/jth.14888

38. lazzerini $\mathrm{p}$, boutjdir $\mathrm{m}$, capecchi. COVID -19, arrhythmias and inflammation. 10.1161/circulationaha.120.047293

39. Chadda K, Ajijola O, Vaseghi M, Shivkumar K, Huang C, Jeevartnam K. Ageing, the autonomic nervous system and arrhythmia: From brain to heart. Ageing Research Reviews. 2018, https://doi.org/10.1016/j. arr.2018.09.005

40. Yu CM, Wong RS, Wu EB, Kong SL, Wong J, Yip GW, Soo YO, Chiu ML, Chan YS, Hui D, Lee N, Wu A, Leung CB, Sung JJ. Cardiovascular complications of severe acute respiratory syndrome. Postgrad Med J 2006;82(964):140-4. https://doi.org/10.1136/pgmj.2005.037515

41. Xiong TY, Redwood S, Prendergast B, Chen M. Coronaviruses and the cardiovascular system: acute and long-term implications. Eur Heart $\mathrm{J}$ 2020. https://doi.org/10.1093/eurheartj/ehaa231 